\title{
Ribes alpinum L. as a unique introduced material for breeding in Russia
}

\author{
Vladimir Sorokopudov ${ }^{1 *}$, Nadezhda Patsukova $^{2}$, and Olga Sorokopudova ${ }^{1}$ \\ ${ }^{1}$ Russian State Agrarian University, Moscow Timiryazev Agricultural Academy, 127550, Moscow, \\ Russia \\ ${ }^{2}$ Belgorod State National Research University, 308015, Belgorod, Russia
}

\begin{abstract}
Ribes alpinum L. has all useful properties (optimal combination of vitamins, sugars, organic acids, pectins) and, due to this, it deserves to be introduced into the breeding process. It was found that, in the conditions of the Belgorod region, Alpine currant develops normally and passes all phenological phases. The long-term variation in the timing of the phase onset is 25 days on the average. The studied forms of Ribes alpinum $\mathrm{L}$. belong to phenologically early plants. In the cultivation for decorative purposes in the conditions of the Belgorod region, 5 forms are identified: large-fruited, compact, erect, erect dissected-leaved and spreading. There are 8 Alpine currant varieties (Evrika, Vorskla, Mulatka, Theodor, Dunyasha, Uslada, Krasnyi Schar, Zara) with a complex of economically valuable characteristics.
\end{abstract}

\section{Introduction}

Ribes alpinum L. is a wild species that we first proposed as a fruit plant. Previously it was considered only as an ornamental species. Early and thick foliage, bright berries that adorn the shrub in summer and autumn, ornamental foliage, ease of reproduction and unpretentiousness make this species a desirable planting material for landscaping. It is used for free-growing or molded hedges, in single or group planting and in topiary art (Sorokopudov, Patsukova, 2008; Burmenko et al., 2009).

It was noted that Ribes alpinum L. has all the useful properties of red currant (optimal combination of vitamins, sugars, organic acids, pectins and nitrogenous substances) and, therefore, deserves to be introduced into the breeding process, since this species is not found in nature in European Russia, but is cultivated as a decorative species in botanical gardens. In connection with the above, the introduction and selection study of the biological features of the forms of Alpine currant is of particular relevance. A comprehensive study is necessary to identify the sources of economically valuable and decorative features, on the basis of which it is possible to create varieties adapted to harsh conditions (Burmenko et al., 2009).

\section{Materials and methods}

* Corresponding author: sorokopud2301@mail.ru 
To identify the adaptability to new environmental conditions, we applied the method of integral assessment, developed in the Department of Dendrology of the State Botanical Garden, which was modified by us to identify the prospects for the introduction of Alpine currant in the conditions of the Belgorod region. The assessment took into account seven bioecological indicators: winter hardiness, preservation of habit, shoot-forming ability, shoots growth regularity and the ability to generative development, as well as decorativeness.

The material for the research was the Alpine currant seedlings which were studied in the field. The main records and observations were carried out according to the generally accepted program and methodology of variety study of berry crops [10].

\section{Results of investigations}

According to the results of a point assessment, the studied samples were divided (Patsukova, 2009) into three groups according to the degree of prospects. The first promising group includes $43.5 \%$ of samples with an assessment from 72 to 80 points. They are characterized by winter hardiness, the ability to intensive seed reproduction (annual renewal by self-seeding) and decorativeness. The second one is average-prospective. It includes $48.7 \%$ of the studied samples, and it also includes plants that retain decorative properties, are capable of seed reproduction, but they are less promising than those belonging to the $1^{\text {st }}$ group, due to the inability to maintain decorative properties throughout the growing season, and also they do not give progenies by self-seeding. The third group is not promising, including samples with a score from 55 to 63 points (3.7\% of samples). They are hardy, capable of seed reproduction, but were not promising primarily because of low decorative qualities (undeveloped bush shape, nondescript flowering).

Based on our observations, we have identified and described the following five phenotypic forms (Patsukova, 2009):

Form A - "Large-fruited". The bush is medium-sized (about $80 \mathrm{~cm}$ ), medium-spreading and of mesotonic structure. Shoots are of medium thickness. Their leaves are medium-sized and dark green. The flowering is nondescript, but productive ( $80 \%$ have fruits). It is characterized by large fruitfulness and rich harvest.

Form B - "Compact". Presumably, it is similar to the form "Pumilum". The bush is short, sometimes medium-sized (about $70 \mathrm{~cm}$ ) and compact. There is pronounced acrotonia in all specimens. The shoots are bluish, thin or of medium thickness. The leaves are small and dark. It is characterized by abundant and spectacular spring flowering, but only $16 \%$ of the fruits started. It is well suited for curly haircuts, creating stamps, intricate shapes, landing on slides and landing as a tapeworm.

Form C - "Erect". The bush is tall (about $110 \mathrm{~cm}$ ), slightly spreading, of mesotonic or basitonic structure. There are few shoots and they are thick grayish; the shoots of the first year are light brown. The leaves are very large, up to $6 \mathrm{~cm}$, and dark. After flowering, 33\% of the berries were formed. The form can be used for planting in groups.

Form C1 - "Erect dissected leaf". Presumably, it is similar to the form "Laciniata". The shoots, shape and structure of the bush are as in form B (about $120 \mathrm{~cm}$ ). It differs from it by very bright beautiful dissected foliage. It blooms, but the form is sterile and does not give berries. The shape, due to beautiful leaves, is good for planting in small groups, just like a tapeworm.

Form D - "Sprawling". Presumably, it is similar to the form "Schmidt". The bush is tall (up to $150 \mathrm{~cm}$ ) and shaped as a ball of a basitonic, sometimes mesotonic, structure. The crown is spreading and dense. The shoots are thin and brown in the first year, and gray- in later years. The leaf is medium-sized and green. The flowering is nondescript, but $80 \%$ have developed fruits. The berries are beautiful, bright, slightly transparent and some are 
with a light stripe. This shape is suitable for haircuts, but it is also good without it (pronounced ball). It can be used to create hedges, in decorative groups and single planting.

The variety of phenitypic forms gives a wide choice in the features of using Alpine currant.

During the research, documents have been identified and are being prepared for the transfer to the SCT of Alpine currant varieties (Eureka, Red Ball, Delight, Dunyasha, Theodore, Zara, Mulaka, Vorskla). All varieties pass the main phenological phases in time. A comparison of the phenological phases of the forms showed that there are no large differences between the forms. The beginning of the growing season was noted from March 28 to April 15, flowering from April 4 - May 10 and fruit ripening - June 26 - July 10.

All varieties are comprehensively resistant to pests and diseases, large-fruited and productive (Table 1).

Table 1. Yield of Alpine currant cultivars in the conditions of the Belgorod region

\begin{tabular}{|c|c|c|c|c|c|c|c|c|c|c|c|}
\hline \multirow{2}{*}{ Cultivar } & \multicolumn{5}{|c|}{ Yield, kg/bush } & \multicolumn{6}{|c|}{ Yield, cntn/ha } \\
\hline & \multirow{3}{*}{$\begin{array}{c}2007 \\
1.5\end{array}$} & \multirow{3}{*}{$\begin{array}{c}2008 \\
1.3\end{array}$} & \multirow{3}{*}{$\begin{array}{c}2009 \\
1.7\end{array}$} & \multicolumn{2}{|c|}{ Average } & \multirow{3}{*}{$\frac{2007}{49.5}$} & \multirow{3}{*}{$\begin{array}{l}2008 \\
42.9\end{array}$} & \multirow{3}{*}{$\begin{array}{l}2009 \\
56.1\end{array}$} & \multicolumn{3}{|c|}{ Average } \\
\hline \multirow{2}{*}{ Euereka } & & & & $1.50 \pm$ & $\pm \quad 0.20$ & & & & 49.50 & & 6.60 \\
\hline & & & & $1.30=$ & $\begin{array}{l}-\quad 1.70 \\
\end{array}$ & & & & 42.90 & - & 56.10 \\
\hline \multirow{2}{*}{$\begin{array}{l}\text { Krasny Shar } \\
\text { (Red Ball) }\end{array}$} & \multirow{2}{*}{1.7} & \multirow{2}{*}{2.0} & \multirow{2}{*}{2.5} & $2.07 \pm$ & $\begin{array}{ll} \pm & 0.40 \\
\end{array}$ & \multirow{2}{*}{56.1} & \multirow{2}{*}{66.0} & \multirow{2}{*}{82.5} & 68.20 & & 13.34 \\
\hline & & & & 1.70 & $\begin{array}{l}-\quad 2.50 \\
\end{array}$ & & & & 56.10 & - & 82.50 \\
\hline \multirow{2}{*}{ Uslada } & \multirow{2}{*}{1.1} & \multirow{2}{*}{1.5} & \multirow{2}{*}{1.7} & $1.43 \pm$ & $\pm \quad 0.31$ & \multirow{2}{*}{36.3} & \multirow{2}{*}{49.5} & \multirow{2}{*}{56.1} & 47.30 & \pm & 10.08 \\
\hline & & & & 1.10 & $-\quad 1.70$ & & & & 36.30 & - & 56.10 \\
\hline \multirow{2}{*}{ Dunyasha } & \multirow{2}{*}{1.4} & \multirow{2}{*}{3.0} & \multirow{2}{*}{3.1} & $2.50 \pm$ & $\begin{array}{ll} \pm & 0.95 \\
\end{array}$ & \multirow{2}{*}{46.2} & \multirow{2}{*}{99.0} & \multirow{2}{*}{102} & 82.50 & & 31.48 \\
\hline & & & & 1.40 & $\begin{array}{l}-\quad 3.10 \\
\end{array}$ & & & & 46.20 & - & 102.30 \\
\hline \multirow{2}{*}{ Theodore } & 1.0 & 2.3 & 2.3 & $1.87 \pm$ & $\begin{array}{l} \pm 0.75 \\
\end{array}$ & 33.0 & 75.9 & 75.9 & 61.60 & & 24.77 \\
\hline & 1.0 & 2.5 & 2.5 & 1.00 & -2.30 & 35.0 & 15.9 & 15.9 & 33.00 & - & 75.90 \\
\hline Zara & 08 & 23 & 23 & $1.80 \pm$ & $\begin{array}{l} \pm \\
\end{array}$ & 26.4 & 75.9 & 759 & 59.40 & & 28.58 \\
\hline Zard & & & & 0.80 & $\begin{array}{l}-\quad 2.30 \\
\end{array}$ & 20.4 & 15.9 & 15.9 & 26.40 & - & 75.90 \\
\hline Mulatka & 0.6 & 0.9 & 1.2 & $0.57 \pm$ & $\pm \quad 0.35$ & 19.8 & 29.7 & 39.9 & 18.70 & & 11.59 \\
\hline мйатка & 0.0 & 0.9 & 1.2 & 0.20 & 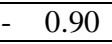 & 19.8 & 29.1 & 39.9 & 19.80 & - & 39.90 \\
\hline Vorksla & 0.9 & 2.4 & 2.3 & 1.87 & $\pm \quad 0.84$ & 29.7 & 79.2 & 75.9 & 61.60 & & 27.68 \\
\hline VOIKSTI & 0.9 & 2.4 & 2.3 & 0.90 & -2.40 & 29.1 & 19.2 & 15.9 & 29.70 & - & 79.20 \\
\hline
\end{tabular}

The highest average yield was recorded in the Dunyasha variety (2.5 kg/bush). In 2007 , the Zara variety was the leader, and in 2008 and 2009, the Dunyasha variety surpassed the rest (3.0 and $3.1 \mathrm{~kg} / \mathrm{bush})$.

The variety of Delight is distinguished by a pleasant taste of cinnamon, the varieties Dunyasha and Red Ball have a refreshing taste with sourness, which is very important for dietary nutrition. According to the large-fruited varieties, the Delight, Red Ball, and Eureka are leading. According to the high content of vitamin $\mathrm{C}$, the varieties Theodore $(75.84$ $\mathrm{mg} \%$ ), Mulatka, (73.45 $\mathrm{mg} \%$ ) and Eureka(72.66 mg\%) were distinguished. According to the high content of the carotenoid lycopene, the varieties Eureka $(8.26 \mathrm{mg} \%)$ and Vorskla $(9.00 \mathrm{mg} \%)$ were distinguished.

\section{Conclusions}

Based on the conducted research, we can draw the following conclusions:

All the selected varieties with a complex of economically valuable characteristics are of interest for the further breeding work in the conditions of the Belgorod region. In the conditions of the Belgorod region, Alpine currant develops normally and passes all the phenological phases. The long-term variation in the timing of the phase onset is 25 days on the average, which is due to the difference in weather conditions. The studied Ribes 
alpinum L. forms belong to phenologically early plants. In the cultivation for decorative purposes in the conditions of the Belgorod region, 5 forms have been identified: largefruited, compact, erect, erect dissected-leaved and spreading. Documents have been prepared for the transfer to the State Commission for Cultivar Testing for 8 Alpine currant varieties (Eureka, Vorskla, Mulatka, Theodore, Dunyasha, Delight, Red Ball, Zara) with a complex of economically valuable characters.

\section{References}

1. V.N. Sorokopudov, N.G. Patsukova, Alpine currant (Ribes alpinum L.) as a promising introducer in the conditions of the Belgorod region. Biologically active compounds of natural origin: phytotherapy, pharmaceutical marketing, pharmaceutical technology, pharmacology and botany, in Proceedings of the International Scientific and Practical Conference, Belgorod, June 30 - July 3 (2008)

2. Yu. V. Burmenko, V. N. Sorokopudov, N. G. Patsukova, T. A. Rezanova, Ontogenetic features of the pre-juvenile phase of some species of genus Ribes L. Biologically active compounds of natural origin: phytotherapy, pharmaceutical marketing, pharmaceutical technology and botany, in Proceedings of the International Scientific and Practical Conference, Belgorod, June 30 - July 3 (2008)

3. Yu. V. Burmenko, V. N. Sorokopudov, D. A. Kolesnikov, N. N. Maslova, N. G. Bulletin of Krasnoyarsk State Agrarian Univ., 1 (2009)

4. V. N. Sorokopudov, Yu. V. Burmenko, T. A. Rezanova, N. G. Patsukova, N. N. Maslova, V. V. Yazykova, E. I. Shaposhnik, Problems of regional ecology 1 (2009)

5. N. G. Patsukova, Indentifying Proceedings of the V International Conference of Young Scientists (2009)

6. N. G. Patsukova, Proceedings of the V International Conference of Young Scientists (2009) 